\title{
Counselors' Supervision: What Helps to Express Their Thoughts?
}

\author{
Siti Kholijah Kassim \\ Department of Educational Psychology \\ and Counseling, \\ Kulliyyah of Education, \\ International Islamic University Malaysia, \\ Kuala Lumpur, Malaysia \\ sitikholijahkassim@iium.edu.my
}

\author{
Haniza Rais* \\ Department of Educational Psychology \\ and Counseling, \\ Kulliyyah of Education, \\ International Islamic University Malaysia, \\ Kuala Lumpur, Malaysia \\ hanrais@iium.edu.my
}

\begin{abstract}
The counseling practicum provides an opportunity for counselors to explore and practice their acquired skills in the actual work setting. Confronting the practicum site, at the outset, it is not uncommon for the practicum counselor to experience great anxiety and trepidation, faced with many challenges and uncertainties, that may linger throughout the course of the practicum. This study is conducted to explore these predicaments, using creative activities as a platform to share their concerns and worries in coping with practicum issues. Thirty participants, 3 males and 27 females, who were attached as practicum counsellors, participated in the study. Data were triangulated from three different sources: from the process journals, scheduled guided journals and drawing activities done during the supervision meetings. Scheduled guided reflective journals refer to the journals that provide a guiding question to respond with the purpose to meet the immediate needs at certain phases of the practicum journey. Journals are scheduled at 4 different phases of the practicum. A Reflective Process journal is one of the tasks done immediately upon the completion of each activity to reflect on the immediate reactions of participants to the activities conducted. Based on the findings, the challenges were categorized into six major themes: Interpersonal relationship, Inadequate Skills, the real Clients, Direct Contact Hours, Report and Documentation and Counselling facilities. The practicum counselors' source of coping can be either internal or external support, or both. The drawing activities during the weekly supervision helped practicum counselors release their tension; whereas the weekly meetings are Stress Releasers for them. Stress during the practicum may be inevitable but the continuous support throughout the supervision and the creativity in providing the platforms and means to enable the practicum counsellors to release and express their issues and concerns, thus helping them cope better through the practicum journey.
\end{abstract}

Keywords: Counseling practicum, supervision, process journals, challenges, coping 


\section{INTRODUCTION}

The counseling practicum is a component in school counseling training that is scheduled toward the end of the study programme. It is scheduled for the undergraduate and postgraduate levels by all universities that offer counseling training. In IIUM, the counseling practicum is a required task to be completed by the third year undergraduate students after completing the requisite courses. They will do their practicum at the secondary schools. The counseling practicum is a required task to be completed by the third year undergraduate students at IIUM. The Educational and Technical Training Committee and the Board of Counselors, Malaysia (2012), defined the practicum as a supervised clinical experience of trainee counselors with the aim of developing their basic helping skills, and to integrate their theoretical knowledge during their study into practice. Going to the field, facing the real clients and trying to apply basic counseling knowledge to practice for the first time have been viewed as a challenge by many counseling students (Aman \& Ahmad, 2010 \& Ruhani, 2008,). A study conducted by Ruhani Mat Min, (2008), indicated that the practicum counselors face three types of challenges, which are one's self, one's relationships and the school culture. Another study conducted by Hamaidi, Al-shara, Arouri, and Awwad (2014), emphasized that in relation to the practicum, supervision and administrative workload are some examples that lead to stress during the practicum.

\section{The Counseling Practicum}

According to the Council for Accreditation in Counseling and Related Educational Programs (CACREP), practicum counsellors must complete a total minimum of 100 clock hours of direct service with actual clients, with 250 hours on-site. Similarly, in Malaysia, the Educational and Technical Training Committee and the Board of Counselors (2012), has stipulated that a minimum period of 252 practicum hours is equivalent to three credit hours, inclusive of 96 hours of face-to-face counseling sessions with the clients (individual counseling, group counseling, marriage and family counseling). At the Kulliyyah of Education, International Islamic University Malaysia, the Bachelor of Education programme specializing in Guidance and Counseling is accredited by the Board of Counselors, Malaysia. The undergraduate counseling students will do their practicum during the third year of studies after completing the pre-requisite counseling courses. They have to complete 252 hours at the practicum site, including 72 contact hours for individual counseling and 30 contact hours for group counselling, within the seven weeks (Haniza, 2012). This is the first practical experience at a real setting before an internship takes place in their semester of the final year or studies.

Earlier studies have consistently shown that counseling students doing their practicum may experience all kinds of challenges This is due to the expectations to complete the direct contact hours and the completion of the required tasks of writing proposals, logbook, session notes, relevant forms and many other documentations. The counseling practicum supervision is compulsory in the training of counsellors (CACREP, LKM, etc). The role of the supervisor as a gatekeeper has become a fundamental requirement in inculcating the responsibility as an educator in counseling (Corey \& Corey, 2017). There is a paucity of literature that shows how this concern is addressed using more creative ways. Perhaps, verbal discussions in supervision 
seem to be the normal practice for a long time, which most likely focused on the tasks assigned to them. On the other hand, counseling professionals are trained to use specific interventions and therapeutic techniques in their practice. Thus, the emergence of new techniques and skills require counselors to adopt new methods in the field as well as to find the best approach with future clients (Peterson, 2010). This evidence suggests that creative art expressive activity may enhance student's ability to explore and articulate their concerns, and to cope during the practicum.

The counseling practicum provides an opportunity for practicum counselors to explore and practice their counseling skills in the real-world setting. When practicum counselors go to the practicum site for the first time, they normally face many challenges and uncertainties that may continue until the end of the practicum. According to Ruhani (2008), engaging in the counseling practicum provides a learning journey for the counseling trainees. It particularly relates to their experiences, applying their knowledge and skills with the new pupils and environment, adjusting the new roles and balancing between their own needs and expectation from others. According to Aman \& Ahmad (2010), before practicum counselors go to the counseling site, the higher institute must make sure that the practicum counselors are prepared with the counseling knowledge, both theoretical practical. It means that practicum counselors must equip themselves with adequate counseling knowledge and skill in order to serve as a professional counselor. According to Jaafar.W (2010), the counselor educators must perform their task with excellence. They must prepare practicum counselors with acute skills that they can use in extreme circumstances such as counseling sessions with high-risk clients.

The practicum counselor will experience role transitions during the practicum period. They need to shift from the role of student to the role of practicum counsellor, and from the university environment to the school environment. Research done by Aman \& Ahmad (2010) conducted with practicum counsellors, exposed some weaknesses of the practicum situation. For example, the university supervisor visits the practicum counselor's site only once. This creates a problem for the practicum counselor because it does not allow sufficient time to consult with the university supervisor and discuss the challenges and difficulties during their practicum. In addition, the requirement to fulfil 500 hours for practicum training is a big challenge to fulfil. Some of the research participants are also school teachers who are pursuing further studies part-time, which makes access and consultation difficult. (Aman \& Ahmad, 2010).

\section{METHODOLOGY}

This research was a qualitative study with purposeful sampling, a sampling procedure in which the researcher intentionally selects individuals and sites to learn and understand the core phenomena (Creswell, 2005). A case study was utilized in order to explore and understand the challenges among practicum counsellors. The supervision activities, specifically the guided reflective journals, provide them a platform to share their concerns and worries in coping with practicum issues. 
Thirty participants from counseling practicum in the academic year were involved in this study. They were 3 males and 27 females who were attached as practicum counselors at selected secondary schools in the state of Selangor and Kuala Lumpur. Data were triangulated and collected from three different sources: from the process journals, scheduled guided journals and drawing activities done during the supervision meetings.

Scheduled guided reflective journals refer to the journals that provide a guiding question to respond with the purpose to meet the immediate needs at certain phases of the practicum journey. Journals are scheduled at 4 different phases of the practicum. Practicum counselors must submit the journals as stated in the deadlines at different stages. The Reflective Process journal is one of the tasks done immediately upon the completion of each activity to reflect on the immediate reactions of participants to the activities conducted. Practicum counsellors meet every Friday for 7 weeks during the counseling practicum journey at the university for group supervisions.

\section{FINDINGS}

\section{Challenges during the Practicum}

Based on the data gathered, there are a number of challenges faced by participants during the practicum. The challenges were grouped into six major themes: Interpersonal relationship, Inadequate Skills, the real Clients, Direct Contact Hours, Report and Documentation and Counselling facilities.

\section{Interpersonal Relationship}

Some practicum counsellors found it a challenge to initiate a relationship with the principal, teachers and administrative staff. Some of the situations shared include:

"During the practicum I had difficulty to communicate with the senior teachers may be because of the location of the counseling unit that was not in the teachers' room so there is a gap that prevents us from mingling with the teachers unless the is any events but it's not enough ..."

"... The thing that affected me and my anxieties is the impression of the other teachers at the school. It is because some of them seemed not to welcome us to the school. So, Ifelt depressed at that time and unmotivated to have practicum there..." (189:1)

"...I also have trouble in dealing with other two counselors at the school. They are not really friendly and as if we are not exist in front of them..." (184:2)

“...The male counselor is cold towards us. He always monitored our room and chased out students who come in a big group. And we were just allowed to do session for only thirty minutes per sessions and then students need to go to class. I felt so dissatisfied and it makes me dislike him a bit. He also locked our room and he kept they key to himself..." (198:1) 


\section{Inadequate Skills}

Practicum counsellors feel the need to have certain skills. The skills are categorized into two: Counseling Skills and Class management Skills. They felt that they need to improve these two skills in order to fulfill their tasks in schools.

"...I also worry about the theory that I prefer to use for my client. I still did not decide and am confuse which theories that I am not comfortable with..." (189:3)

The practicum counselors found themselves unable to control the class when they took over relief classes.

“...What makes me worry is when I have relief classes. Sometimes I don't know what to do in the classroom..." (192:2)

“...I do have some problems with relief classes. I am not really confident to talk in front of the students...” (194:5)

"...I can regard as my first class is a failure because I cannot handle the students...” (205:1)

" ...every day I will think how to handle the student...how to tackle them" G1P3FGD1

\section{Real Clients}

Having a real counseling session with real clients makes practicum counselors anxious. During class, they do not face real clients and mostly practiced sessions with their friends. But during the practicum, direct contact with clients is one of the tasks that they must fulfil for the contact hours. The followings are some examples of their quotes:

“...Then, I was also afraid of doing the session with client. Now, I have to face the actual client. It might be bad for the client if I failed to guide him. I noticed that, sometimes, I always give suggestion to client even though I know that we should never do that..." ( 185:2)

“...I am also quite confused and blurred about the procedure before conduct counseling because that is my first time...” (186:2)

“...The things that I worried most after few weeks of practical are, firstly, related with the session..." (194:1)

"...I started to realize about my weakness in conducting the session and it make me feel stress because I not satisfied with my session...” ( 201:1)

\section{Client Contact Hour}

It is the most repeated challenges shared by many. Contact hour here refers to the time whereby the practicum counselors attend the face to face session with the clients, which includes the hours they spent in individual counseling, group counseling, classroom group guidance or any counseling programs at the site (Rais, H. 2020). Most participants worried that they are not able to complete the hours within 7 weeks of practicum. 
communicates with her family mostly in English. Participant 2 speaks Bahasa Melayu with his family while Participant 3 speaks in both Bahasa Melayu and English (mixed).

"...I do not think that I can finish the contact hour session, unless we must interview the students at night!...” (184:1)

"...I feel so worried about searching client to fulfil individual counseling contact hour..." (186:1)

"... what makes me really worry is the total of site contact hour. I am worried if I cannot fulfill the total contact hours that is compulsory to us. However, I need to stay back at the school until 5.00 or 6.00 p.m. to conduct the counseling session ..." (189:2)

"...the anxiety that I have during this practicum is about the task that we as the guidance and counseling student should do. As we know, we should make seventy hour of the individual counseling session and thirty hours of group guidance including the group counseling or relief class. However I think I am not being able to complete this task and it makes me worried about it..." (190:1)

“... My concern is, will I be able to fulfil the requirement hours? ...” (193:2)

“... I will not have enough time to complete individual and group counseling hours. I just get a few clients for the first week ...” (199:1)

\section{Reports and Documentation}

The practicum counselors worry about the filing system of their clients. Each client has their own file if they have counseling sessions at school. Practicum counselors are responsible for the files' confidentiality. They also have to log their hours in the logbook. Additionally, they feel the challenge to submit the tasks as scheduled.

“...Another thing that worried me is updating logbook and filing. As time passes, there will be a bunch of work to be done. So, I am extremely afraid that if I do last minute job I might fail to updating the logbook and filing. However, I have limitation of time since last week. So, it keeps bothering me...” ( 185:1)

“...Before this, I was very in trouble about the documentation aspect. So I am not ensuring about the procedure to go through...” (200:2)

\section{Counseling Facilities}

Counseling facilities at the practicum site, like counseling room, transportation and financial support at the practicum can affect the services provided to students. Some schools do not have proper counseling rooms for practicum counsellors to conduct the counseling sessions.

“...Tense... with small room. Don't know how to conduct counseling session in that room...” G1P6FGD1

“... We stay like in the prison"... 


\section{Their Coping Strategies}

Getting support is one of their coping strategies to overcome the challenges. There are two types of support they found helpful derived from the shared themes; internal and external support.

Internal support can refer to the alternative ways that students do by themselves. For example, they know that they lack knowledge and skills, so they try to search for related information by reviewing the textbook theories and surfing the Internet for further information.

“...also need to revise back about the theories of counselling...”. (2:18)

“...I study about theory and skills...” (18:11)

"...I search about the school and the teacher in the internet. So, it helps me a little bit before start the practicum and it reduce my nervous. ..." (18:5)

The external support comes from colleagues and friends. For example, having connections with the previous seniors asking them about the practicum setting will help them prepare better. In addition, having a good relationship with the partner and colleagues can help practicum counselors deal with their challenges. For example, looking to the senior teachers or counselors at the practicum site will help make the practicum less stressful. The support also includes guidelines for conducting the counseling session and managing the challenging cases.

"...I called my friend that already has done the practicum last year. She gives me the example of what I should do and what I should write in the log book..." (1:6)

"...I think I might have a good rapport with the teachers in terms of communication...” (20:6)

“...There are two counselors who able to help and guide me about all the involved procedures at that school. The procedure and system of the counseling unit is so systematic and that makes my work become easier as I just have to follow the procedure. ..." (186:3)

\section{Benefit from Drawing Activity}

Expressing their feeling through drawing activities during the weekly supervision helped practicum counselors release their tension. With drawing, they are free to express themselves by using various colors and themes. They became aware of their fears and concerns. They can articulate their feelings, especially the ones who are shy and reserved. Coming back to campus for the weekly supervision helped them recoup and stabilise. Sometimes, after doing the drawing activity, they get new ideas from others on how to apply it at the practicum site.

“...I am able to express my feeling when I enter for the first time in class through the drawing activity... " G1 P3 A2

“...It is a great for me to come to class and do the activities today..." G1P4 A2

“...Aftelisting down the challenges and the needs, I finally find the solution on how to solve those issues...” G1 P5 A2. 
"...I feel that this process really helpful to me to discuss and shared experiences about practicum. After having the discussion, I got new idea, new spirit and new experiences from others..." G2P13 A2

\section{Weekly Meetings as Stress Releasers}

Coming back to campus every week is a great stress releaser to them. Sharing weekly experiences in the group supervision, practicum counselors can express their concerns and issues regarding the site on a weekly basis. The shared experiences help their colleagues who face similar issues. For those who have problems during the practicum, this time can be used for commiserating and information sharing. They also share different ideas and modules that can be used in the relief classes.

"...By having this class, it bring me into the right track, what we have to do in school, what are the task that we have to finished. How and what we have to be prepared. There are also info in how conducting the session. How we want to handle the client..."

“... I get a lot of knowledge from experiences of my friends..."

"...I have get ideas about how to deal with the student and what kind of activity I can conduct ..."

“...I am able to listen my friends precious experiences which make me feel I am kind of lucky to be in my school..."

"...We can share the module and we can practice in class..."

\section{DISCUSSION}

\section{Types of Multimedia Tools Chosen by Students in Building English Vocabulary}

Based on the findings, it shows that practicum counselors do face some challenges and difficulties during all phases of their practicum. The circumstances differ from one student to another. The challenges they faced range from interpersonal relationships with teachers at the practicum site to their skill deficits, from their counseling skills and classroom management ability to the documentation system. However, the most frequently cited problem is related to their accumulation of direct contact hours to be collected during the practicum. This comes out as no surprise because they are worried that they are not able to collect 250 site hours, including 100 hours with clients. During the practicum, they encountered problems related to the practicum site such as improper venue to conduct the counseling session, financial support and transportation to go to the practicum site.

The findings show that to cope with these challenges, practicum counselors learned to be proactive through searching for information and resources on the Internet, being more creative in their strategies, reviewing their lecture notes and books to keep up with the knowledge of theories of counselling. Most importantly, finding friends and practicum supervisors to be their greatest source of support. 
The weekly group supervision meetings were found to be an important $\backslash$ medium for practicum counselors to share their challenging experiences at the sites. They found the time given during the supervision provided them the opportunity to express themselves through the drawing activities and journal reflection. The practicum counselors managed to cope with those challenges when they have a good chemistry and relationship with their partner at the counselling sites.

\section{Implications for Counseling Supervision}

The main purpose of the counseling practicum is to build and develop the basic knowledge and counseling skills for practicum counselors and to integrate their theoretical professional knowledge acquired during study with practical real-world application.

The study has several implications that can be used to improve the counseling practicum program in the future. We identified 3 main entities instrumental to the proposed implications.

\section{Training Providers and Counselor Educators}

In order to improve and enhance counseling skills, specific training or a professional orientation program prior to the practicum will provide the necessary input to prepare them better before entering the field.

Additionally, the roles as practicum counsellors must be clearly defined and elaborated during this program or at the briefing, so that they are ready and prepared and are better equipped to embark on their journey, thus committed in carrying out their roles and responsibilities as practicum counsellors.

The supervision should also focus on mental health matters related to both professional and personal development of the future counsellors.

\section{Counseling Settings:}

Support from the site supervisors and site administrators (school administrators) is important. Senior counselors' ability to coach and impart new skills at the real setting is important. Some challenges involved unclear expectations from the settings. The university supervisor must have good communication with the site supervisors in order to have continuity in helping practicum counselors to fully experience the real sessions.

\section{Board of Counselors (Lembaga Kaunselor Malaysia):}

The findings indicated that practicum counselors have difficulties in fulfilling the contact hour required by the highest authority in the counseling field. They also faced challenges in terms of counseling skills, and lacking of classroom management skills. In addition, they have a big problem dealing with the real client in actual counseling sessions because they don't know to apply the counseling skills into the practice. Sometimes they feel that they failed to be a counselor because they cannot help their client. According to Soykurt (2010), in order to overcome some problems, each practicum student interpreted his/her problems in the way that he/she could manage to change. The required hours set need to be revised. Very often 
practicums are more concerned with the quantity and neglect the quality. It is therefore suggested that LKM review the required hours and consider the stress that has caused all the practicum counsellors in Malaysia. Less is more.

\section{CONCLUSION}

Challenges can vary from one practicum counselor to another. The challenges if not managed effectively can dampen the motivations of future counsellors. It is crucial to be able to channel one's struggle during the practicum in order to get the best out of these short attachments. From this study, it is evident that practicum counselors need the continuous support from the supervisors and the need to share with someone.

Funding: The writers would like to thank IIUM for the internal grant, RIGS16-192- 0356 Project Title: "Exploring the Anxiety of the Practicum Counselors by Using Creative Arts" which allowed us to undertake the study and make the publication of this work possible.: 


\section{REFERENCES}

Accreditation Procedures Manual for Counseling and RelateEducational Programs: The 2009 CACREP Standards

Aman, R. C., \& Ahmad, N. S. (2010). Counseling practicum in producing excellent counselors, $5,1028-1032$.

American Counseling Association. (1990). Standards for Counseling Supervisors, 69(October), $30-32$.

Barki, B.G., \& Mukhopadyay, B. (1991). Guidance and counseling: A manual. India: Sterling Publishers Private Limited.

Council For Accreditation of Counselling and Related Educational Programs (2009). Alexandria, Va: Author

Educational, C. for A. of C. and R., \& (CACREP), P. (2009). 2009 Standards (pp. 1-63).

Hamaidi, D., Al-shara, I., Arouri, Y., \& Awwad, F. A. (2014). Students- teachers Perspective of Practicum Practices and Challenges. European Scientific Journal, 10(13), 191-214.

Lembaga Kaunselor Malaysia. (2012). Piawai Kelayakan dan Latihan Kaunselor 2012.

Marzuki, W.W.J. (2011). Social and the counseling performance among trainee counselors in Malaysia, 30, 512-516.

Rais, H. (2021). Counseling Practicum and Internship: Supervision Guidelines for Counselors and Interns. IIUM Unpublished

Ruhani Mat Min. (2008). Counseling Practicum: Issues and Challenges. Malaysia: Penerbit, Universiti Malaysia Terengganu.

Soykurt, M. (2010). Practicum students' life in a nutshell. Procedia - Social and Behavioral Sciences, 2(2), 5313-5325. 